\title{
SOBRE A SUPERVISÃO EM PSICANÁLISE: RELENDO FREUd A PARTIR DE LACAN
}

\author{
ON SUPERVISION IN PSYCHOANALYSIS: \\ REREADING FREUD FROM LACAN
}

ACERCA DE LA SUPERVISIÓN EN EL PSICOANÁLISIS: UNA RELECTURA DE FREUD DESDE LACAN

Maria Cristina Poli* Venicius Scott Schneider**

\section{Resumo}

O presente artigo visa desenvolver o conceito de supervisão a partir do sonho da "Injeção de Irma", ao ressaltar a frase descrita no sonho: "chamo imediatamente o Dr. M". Reconhece-se nesta a busca de Freud por um saber sobre a condução do caso clínico. Busca-se, assim, ao longo do artigo, desdobrar diferentes perspectivas sobre a supervisão a partir da análise desse sonho. Indica-se, fundamentalmente, o modo como ele expressa o deslocamento de Freud de um apelo ao mestre e à ciência para a pergunta pelo desejo. Movimento este análogo ao que se espera em um percurso de supervisão clínica no contexto da formação de analistas.

Palavras-chave: supervisão; sonho; direção da cura; transferência; clínica psicanalítica.

\section{Abstract}

The present work intends to develop the concept of supervision starting with the dream of the "Injection of Irma", pointing out the statement depicted in the dream: "Call Dr. M immediately". The search of Freud for the knowledge of the conduction of the clinical case is recognized in this statement. In this way,

\footnotetext{
* Universidade Federal do Rio de Janeiro, Rio de Janeiro, RJ, Brasil; Universidade Veiga de Almeida, Rio de Janeiro, RJ, Brasil.

** Universidade Veiga de Almeida, Rio de Janeiro, RJ, Brasil.
} 
it is aimed to unfold different perspectives about the supervision assuming the analysis of this dream throughout the article. The main idea of this article is to show the passage of the question to the master and the science to the question for the wish. It is expected analogous movement in the clinical supervision in the context of analysts' training.

Keywords: supervision; dream; cure direction; transference; psychoanalytic clinic.

\section{RESUMEN}

Este artículo tiene como objetivo desarrollar el concepto de supervisión teniendo en cuenta el sueño de "la inyección de Irma", enfatizando la frase descrita en el sueño: "apresuradamente llamo al Dr. M". Se reconoce en esta frase, la búsqueda de Freud en relación al saber sobre la conducta de un caso clínico. Uno de los objetivos, por lo tanto, en todo el artículo, es implementar diferentes perspectivas sobre la supervisión del análisis de este sueño. Indica básicamente como el sueño expresa el desplazamiento de la apelación de Freud en relación con el maestro y la ciencia para cuestionar el deseo. Este movimiento es análogo a lo que se espera en un curso de la supervisión clínica en la formación de los analistas.

Palabras clave: la supervisión; sueño; dirección de la cura; transferencia; clínica psicoanalítica.

\section{Introdução}

A supervisão em psicanálise passou a ser gradualmente considerada na história como um dos três pilares da formação psicanalítica, juntamente com a própria análise e o estudo de textos. Inicialmente, era exercida como uma conversa amigável para tratar de questóes relativas aos impasses que surgiam no trabalho com a clínica. Segundo Vegh (2001/2008, p. 42) um dos primeiros supervisionantes da história da psicanálise, Stekel, ao finalizar seu tratamento com Freud, solicitou a ele que pudessem continuar se encontrando com o intuito de discutir sobre a direção da cura de seus pacientes.

De informal essa fala passou a lugar de formação institucional obrigatória com a criação do Instituto de Berlim, que a tornou uma atividade que necessariamente deveria fazer parte da formação do analista. Com a escola lacaniana tal atividade, apesar de deixar de ser exigida e controlada institucionalmente, permaneceu como um ponto crucial na formação, sendo exercida de modo sistemático. 
Tal fato marca que o lugar da supervisão está assegurado como base de formação. Porém seu estatuto segue indefinido: não se trata somente de um ensino teórico, nem unicamente da transmissão de uma técnica; situa-se propriamente na interseção dos dois campos, enlaçados no geral da teoria interrogada pelo singular da clínica.

O que chama a atenção quanto a este fundamento da formação psicanalítica é a produção textual relativamente limitada quanto a um tema básico. Neste sentido, vale retomá-lo procurando situar sua função a partir da conceituação psicanalítica. Podemos, com esse intuito, situá-lo como fazendo parte do momento de criação da psicanálise, mais especificamente no sonho em que Freud diz ter descoberto a significação dos mesmos.

\section{Prolegômenos}

À guisa de esclarecimento poder-se-ia formular uma pergunta: por que utilizar como referência principal para fundamentar uma concepção de supervisão em psicanálise unicamente em Freud e Lacan e náo incluir outros autores visando entabular uma discussão conceitual? Freud sem dúvida estabeleceu em alguns textos um debate com outros autores, pois pretendia, ao tomá-los como contraponto, poder fundar um campo até então inexistente, a saber: a psicanálise. Esta somente passou a ter "sobrenome" (freudiana, lacaniana, kleiniana, etc.) após a morte de Freud em 1939. Por isso, entenda-se que, ao se falar em psicanálise até aquela data, a referência é estritamente freudiana. A invenção da psicanálise concerne unicamente a ele e a ninguém mais, pois, fundado um campo no qual se explicita um modo específico de abordar um problema, cabe aos que vêm depois articular os conceitos e eventualmente produzir um acréscimo, o que é raro: normalmente, ao operar com os conceitos fundamentais amplia-se o campo, não se funda um novo, pois, quando se desvela uma verdade não há outra que seja mais verdadeira e, portanto, a ultrapasse.

Freud, ao delimitar o campo da psicanálise, constitui um objeto que até então não existia nos termos por ele construídos, o que implica que a problemática trabalhada só fazia sentido ao se ordenar a partir dos fundamentos por ele criados. Em suma, com novos operadores surgem novas perguntas que só fazem sentido ao serem ordenadas nesse contexto.

Nesse ponto o motivo do uso do segundo autor, Lacan, deve-se ao fato de que este constrói, a partir do campo freudiano, uma forma específica de conceber a psicanálise que coloca problemas concernentes ao modo de concepção dos con- 
ceitos, pois estes podem ser discutidos desde outras vertentes psicanalíticas, mas não como uma prerrogativa essencial, eventualmente como uma opção.

Isso não quer dizer que um texto não possa ser lido desde um contexto que pode ser elaborado a partir do que o texto não diz, mas pressupóe. Assim, tanto Freud como Lacan escreveram textos que só fazem sentido a partir dos problemas e conceituação por eles levantados que discutem os impasses próprios ao campo doutrinal. Dessa premissa parte o modo como foi concebido este artigo: ele diz respeito a uma forma de relançar a questáo sobre supervisão mencionada por Freud como um elemento importante na composição da formação psicanalítica, que é composta por análise pessoal, estudo dos textos fundamentais e supervisão. Em sua obra, pode-se destacar dois momentos de concepção quanto à supervisão, ou seja, como um modo de treinamento no qual aprende-se sobre o caso com a supervisão de um analista reconhecido (Freud 1918/1972) e um outro no qual se constata que o analista só pode levar seu analisante até onde ele próprio já foi, sendo a contratransferência, segundo Freud, correspondente aos "acidentes" da subjetividade do analista que aparecem atrapalhando o processo analítico (Freud 1910/1972).

Lacan retomará a proposta freudiana a partir de novas categorias conceituais como real, simbólico e imaginário, ordenadas de modo a estarem encadeadas de acordo com um tipo específico de nó, chamado borromeano pela característica de ser uma cadeia na qual, ao ser cortado um elo, produz-se automaticamente o desligamento dos outros. Outro conceito é o de "objeto a", que seria a principal contribuição que Lacan considera ter fornecido à psicanálise e que foi abordada através do estudo da divisão entre o olho e o olhar para torná-lo um conceito operativo.

Evidentemente seria impossível desenvolver todos esses conceitos num artigo, porém são eles que formam a base deste texto. $\mathrm{O}$ que nos interessa, sobretudo, é partir da supervisão como estando ligada etimologicamente ao campo da visão e retomar a necessidade de uma fundamentação da função do quadro, no caso o dito "quadro clínico". Entendemos que o trabalho com a transferência implica que o próprio analista o componha, para isso devendo figurar aí o que é próprio de seu desejo (também tornado um conceito por Lacan, formalizado pelo que ele denominou de "desejo do analista", modo como retomou a contratransferência para torná-la um conceito operativo, tirando-a do contexto de simetria que lhe era conferido).

O desejo do analista pode ser identificado na tela formada pelo modo como é composto no quadro. Neste artigo, nós o abordamos pela imagem do sonho da injeção em Irma, realização de desejo que aparece como reprovável a 
Freud ao indicar seu interesse pessoal em Irma na medida em que o impede de direcionar a cura para o que o próprio sonho aponta como real. Uma das funçóes da supervisão seria a de permitir situar o modo como ali onde o ato analítico deviria advir interveio o desejo do praticante, desviando a direção da cura de seu norte.

Portanto, partimos neste texto da escolha de um recorte de um campo conceitual especificamente freudo-lacaniano ordenado a partir de uma discussão interna a essa doutrina na tentativa de abordar por um novo prisma a problemática que envolve a supervisão sob tais fundamentos. Valemo-nos para isso do sonho da criação da psicanálise, no qual se pode também destacar de forma analógica um elemento da formação que é imprescindível, denominado supervisão.

\section{"Chamo imediatamente o Dr. M."}

O sonho da "Injeção de Irma", que consta na "Interpretação dos sonhos" (Freud, 1900/1972) como "um sonho exemplar", pode ser denominado de sonho inaugural da psicanálise, pois foi a partir dele que Freud diz ter chegado à conclusão de que um sonho é uma realização de desejo. Ele chega a manifestar sua vontade de que uma placa fosse escrita no frontispício da casa onde teve o sonho. Nela deveriam constar os seguintes dizeres: "Aqui, em 24 de junho de 1895, o segredo dos sonhos revelou-se ao Dr. Freud" (1900/1972, p. 130).

Esse também é o sonho que marca uma virada de Freud com relação a seu trabalho anterior, o "Projeto para uma psicologia científica", de 1895, no qual pretendia elaborar uma psicologia para neurólogos de acordo com a conceituação científica da época. Para criar a psicanálise precisará abandonar essa filiação e metaforizar o trabalho do projeto. Faz isso ao criar o inconsciente, que é composto de pensamentos de cuja existência não se sabe, mas que determinam a ação humana. Tem-se notícia de suas manifestações nos sonhos, chistes, atos falhos e sintomas, expressões que de algum modo fazem parte da vida de todos.

Freud estava imbuído, quando teve o sonho dito "exemplar", em desvendar os mistérios da histeria, da qual a ciência da época possuía uma explicação orgânica de que ele discordava. No preâmbulo do sonho descreve que atendia a uma jovem senhora que mantinha laços de amizade com a família. Ele inicia esclarecendo o problema instalado ao se submeter a tais circunstâncias, que limitam a liberdade do analista pelas pressóes impostas pelas relações de proximidade, que reduzem a autoridade do praticante. $\mathrm{O}$ resultado de tal tratamento obteve êxito parcial em virtude, sobretudo, da permanência dos sintomas somáticos. Na época, Freud não tinha um claro critério dos indicativos de um término de trabalho 
e propôs à paciente uma solução aos sintomas que gerou uma discórdia entre eles. A paciente relutava em aceitar tal "solução" e provocou a interrupção do tratamento a partir das férias de verão.

$\mathrm{Na}$ sequência de tais acontecimentos, Freud recebeu a visita de um colega que ele denomina Otto - na verdade o pediatra da família chamado Oscar Rie (Gay, 1988, p. 91). Este teve contato com a família de Irma e diz a Freud que ela não melhorou completamente. Freud percebe uma certa recriminação na fala do doutor, mas não dá maior atenção ao fato. Na mesma noite, em 23 de julho de 1895, Freud escreve a história do caso para Dr. M. (Breuer, segundo Gay, 1988, p. 91), a fim de justificar-se pelo resultado do tratamento. Situado o contexto em que o sonho ocorreu, de acordo com as indicaçóes dadas pelo próprio Freud, passemos ao relato do sonho:

Um grande salão - numerosos convidados a quem estávamos recebendo. - Entre eles estava Irma. No mesmo instante, puxei-a de lado, como que para responder a sua carta e repreendê-la por náo ter ainda aceitado minha "solução". Disse-lhe: "Se você ainda sente dores, é realmente apenas por culpa sua." Respondeu ela: "Ah! se o senhor pudesse imaginar as dores que sinto agora na garganta, no estômago e no abdômen... - isto está me sufocando." - Fiquei alarmado e olhei para ela. Parecia pálida e inchada. Pensei comigo mesmo que, afinal de contas, devia estar deixando de perceber algum distúrbio orgânico. Levei-a até a janela e examinei-lhe a garganta, e ela deu mostras de resistências, como fazem as mulheres com dentaduras postiças. Pensei comigo mesmo que realmente não havia necessidade de ela fazer aquilo. - Em seguida, ela abriu a boca como devia e, no lado direito, descobri uma grande placa branca; em outro lugar, vi extensas crostas cinza-esbranquiçadas sobre algumas notáveis estruturas recurvadas, que tinham evidentemente por modelo os ossos turbinados do nariz. Chamei imediatamente o Dr. M., e ele repetiu o exame e o confirmou... O Dr. M. tinha uma aparência muito diferente da habitual; estava muito pálido, claudicava e tinha o queixo escanhoado... Meu amigo Otto estava também agora de pé ao lado dela, e meu amigo Leopold a auscultava através do corpete e dizia: "Ela tem uma área surda bem embaixo, à esquerda." Indicou também que parte da pele do ombro esquerdo estava infiltrada. (Notei isso, tal como ele fizera, apenas do vestido.)... M. disse: "Não há dúvida de que é uma infecção, mas não tem importância; sobrevirá uma disenteria, e a toxina será eliminada."... Tivemos também pronta consciência da origem da infecção. Não muito antes, quando ela não estava se 
sentindo bem, meu amigo Otto lhe aplicara uma injeção de um preparado de propil, propilos... ácido propiônico... trimetilamina (e eu via diante de mim a fórmula desse preparado, impressa em grossos caracteres)... Injeçóes como essas não deveriam ser aplicadas de forma tão impensada... E, provavelmente, a seringa não estava limpa (Freud, 1900/1972, p. 115).

\section{Três momentos da supervisão}

Nesse sonho é possível destacar três momentos no modo de conceber a supervisão. No primeiro há o pedido, que aparece na ordem da necessidade, da urgência, diante da angústia de Freud ao se deparar com a visão da cavidade bucal de Irma. Nessa perspectiva, ele está diante da constatação de que o saber que possuía não era suficiente para que se situasse diante do que a clínica revelava. O que o leva a chamar - destaque-se o caráter de urgência - imediatamente (esse é eventualmente o efeito que a clínica causa ao praticante) o Dr. M. (sabemos tratar-se de Breuer). Freud lhe atribuía um notório saber na vida em vigília, porém no sonho ele o apresenta como alguém muito fragilizado. Além disso, como acima mencionado, Freud havia apresentado uma soluçáo para a questão de Irma que ela havia rejeitado. Ele não se pergunta sobre o que poderia estar errado no seu modo de dirigir a cura. Atribui o fracasso a uma recalcitrância da paciente em aceitar o que ele propôs.

Ele estava numa encruzilhada, visto que, para esclarecer o que se passava com Irma, ver-se-ia diante da necessidade de interrogar o status quo científico. Por outro lado, ele precisava da presença de um outro para estabelecer o quadro tal como se apresentava e legitimar sua interpretaçáo. Assim, na noite anterior ao sonho, escreveu para Breuer na tentativa de justificar o estado da paciente. Era óbvio que, para Freud, ele ainda ocupava um lugar de autoridade da qual esperava reconhecimento.

Nesse momento percebe-se um outro viés da demanda de supervisão que se mantém atual e que diz respeito a alguns impasses de sua inscriçẫo institucional. $\mathrm{Na}$ instituição de formação de analistas, a supervisão pode se pautar pela busca do reconhecimento do Outro de um lugar que se quer ocupar. Os efeitos de alienação decorrentes se sustentam na demanda, dirigida aos semelhantes, dos índices que garantam a integridade do eu (o que é o inverso do que se espera da posição de um analista). Podemos lembrar aqui o silogismo de Lacan (1966/1998) a propósito do tempo lógico: como todo grupo só se forma a partir de três - nenhum dos quais sabendo quem é por não encontrar respostas nas próprias palavras -, 
busca-se nos semelhantes o traço com o qual se possa se identificar e diferenciar. Tal traço se situa também como um ponto ideal que permitirá a unidade do grupo (Freud, 1921/1972).

No sonho de Freud percebe-se que o problema é que esse traço - unário - fica interrogado pela questão - seu objeto - sobre a qual ele está debruçado: a histeria. A histérica tem por vocação interrogar o saber do mestre que, no caso em questão, seria a ciência sustentada pelos pares de Freud. Ao pôr em questão a ciência, e sem ter ainda fundado uma comunidade analítica, a quem Freud se identificaria senão à própria histérica? É desde essa posição, portanto, que ele produz sua demanda e a endereça ao Dr. M.

Freud não desenvolve suficientemente em suas associaçóes o lugar que Fliess ocupa nesse sonho, mas essa relaçáo era o que mantinha o que se denominou de sua análise. Pois Fliess, pelo modo como é descrito por Gay, apresentava uma atitude de acolhimento sem crítica que facilitava o avanço de Freud nos impasses em que se encontrava ao mesmo tempo que permanecia cego em relação à transferência para com ele. Aqui entramos no que seria o campo da suposta autoanálise de Freud. Não aprofundaremos esse ponto, no entanto, pois não é o foco de nossa análise neste artigo.

Como mencionamos no início, ao se retomar a indicação que a abordagem do sonho da injeção de Irma permite, adentra-se em diferentes modos de conceber a questão da supervisão; destaque-se em particular a da supervisão como possibilidade de interrogar a direção dada pelo praticante a partir das concepçóes que norteiam sua escuta. Aqui, Freud deixa bem clara sua concepção na época sobre a histeria e o modo de tratá-la: basta comunicar à paciente a solução e o sintoma deverá se desfazer. As concepçóes de transferência e recalque ainda estão para ser elaboradas. Percebe-se então um clínico que, naquele momento, esquece a necessidade de inclinar-se sobre as manifestaçóes da paciente para relançar a fala até que a verdade do inconsciente surja. Freud não tem ali uma pergunta a Irma, tem somente a reprovação de todos a sua volta que ressaltam sua insuficiência em dar uma resposta. Desse modo é a ele que cabe saber e não ao que possa advir da fala da paciente, que fica impedida pela soluçáo.

No terceiro momento a ser considerado sobre a supervisão, constata-se que a solução condensa tanto aquela dada pela interpretação por Freud à paciente, quanto a fórmula da injeção, a trimetilamina. Losung, a solução, pode ser entendida tanto como o líquido que é utilizado na seringa, quanto a resolução de um problema (Lacan, 1954-1955/1985). Desde essa perspectiva, é possível estabelecer um paralelo entre o problema do tratamento de Irma e o sonho de Freud. Para ele a solução envolvia a questão da sexualidade que somente encontrava eco 
de aprovação em Fliess. Sabe-se, através da pena de Gay (1988), que Irma era na verdade Emma Eckstein, a quem Freud fez questão que Fliess operasse por considerar que sua patologia envolvia o nariz. Após a cirurgia Emma passou mal e foi encaminhada a outro especialista, que descobriu na sua cavidade nasal algo como meio metro de gaze esquecida, que ao ser retirada provocou uma hemorragia, a qual levou Freud a passar mal.

Chega-se assim ao ponto em que a referência ao Outro - Breuer, Fliess claudica e mesmo esse que apoia mostra sua inconsistência. Mas o que interessa nesse momento a Freud é a sua paixão de querer ser reconhecido, de querer curar a qualquer custo. Isso que fica evidenciado na parte do sonho em que aparece a seringa suja: suja por seu desejo de curar. Aí emerge a solução, que está na própria palavra que deve ser dada àquela que fala e não ao cientista que quer chegar a ela mesmo que à custa do apagamento do sujeito. Nesse ponto, conforme nos indica Lacan (1954-1955/1985, p. 209), em que a ambição excedeu a ponto de se interpor na direção da cura, aparece a contratransferência como um obstáculo.

Ao operar com um saber imposto, o mestre depara-se com sua condição de impotência. A histérica, desobediente, se opóe à cura que o mestre lhe ordena. Tal é o impasse a que chega um tratamento dirigido seja pelo discurso do mestre, seja pelo discurso histérico. Somente o discurso do analista poderia provocar um giro no modo como se situam os lugares de forma a restituir o lugar do saber à verdade da fala de Irma. Com essa operação verifica-se que "ali onde deveria haver o desejo do analista encontra-se o eu de Freud". Será que poderíamos estabelecer nessa fórmula o avesso do conhecido lema freudiano da $31^{\text {a }}$ conferência, "A dissecção da personalidade psíquica": Wo Es war, soll Ich werden (Freud, 1932/1972, p. 102)?

Foi Lacan quem retomou essa máxima que resume o dever do analista e lhe conferiu um modo de leitura que resgata o gume dos conceitos psicanalíticos (Lacan, 1966/1998, p. 418). Dela havia a tradução do inglês para o francês nos seguintes termos: "O eu deve desalojar o isso" (Lacan, 1966/1998, p. 591). Ideia absolutamente diversa da proposição freudiana que não considerava que $I c h$, em alemão, tanto designa o ego, formado a partir das identificaçóes, como o sujeito do inconsciente (e que, com Lacan, concebe-se como "uma questão"). Desse modo temos a proposição por Lacan da seguinte tradução: "ali onde o inconsciente estava, o sujeito, como questão, deve advir".

Foi justamente esse passo que, no tratamento de Irma, Freud não pôde dar. Eis aí o resultado que poderíamos chamar de ponto cego do analista na direção de cura. Pois, ali onde aparece o corpo de Irma, caberia ao analista antepor uma questão para que a solução brotasse da boca de Irma, através da fala. 


\section{Supervisáo, resgate da experiência}

Sob outra perspectiva, vale considerar que o elemento que permitiu o presente trabalho acerca da funçáo da supervisão foi um resgate do campo dos sonhos. Como postula Freud, os sonhos são a via régia para o inconsciente (Freud 1900/1972, p. 647); é a partir dessa análise que se dá, portanto, o surgimento de uma nova dimensão no campo do saber: a psicanálise. Qual foi a manobra efetuada nesse experimento que permitiu tal transformação? Como uma primeira resposta poder-se-ia adiantar: a fala do sonhador sobre seu sonho. Caso Freud fizesse o que esperava de Irma - aceitasse a soluçáo imposta pelo discurso - nada saberíamos de tal sonho. Ao contrário, ele, a partir do seu relato, resgatou-o do campo do indeterminado, trazendo-o para o lugar de enigma para assim pode aceder ao sentido de sua experiência. Ele o recupera do lugar de resíduo do sono para considerar que ali há uma significaçáo outra que o habita e que diz respeito ao desejo do sonhador - a que só se tem acesso pelo exercício da fala.

Assim procedendo, na interpretação dos sonhos - tal como em uma sessão de supervisão, poderíamos acrescentar -, constata-se a construção de uma realidade que até então não existia. $\mathrm{O}$ estatuto dessa realidade implica que esteja formada por uma amarração específica composta pela apresentação de aspectos do imaginário, marcados pela relação dual, do simbólico, pelo estatuto do terceiro que permite a suposta relação, e do real, como ex-sistência ${ }^{1}$ que situa os limites de suas possibilidades.

O campo da realidade que se constrói através da palavra vai se estabelecendo a partir da descriçấo do que pode ser considerado como um relato do caso. Isso pode ser observado de forma inaugural no sonho de Freud, mas vale para todas as situações de supervisão. Tal relato vem permeado pela elaboração efetuada pelo praticante, assim como também a escuta está predeterminada a destacar elementos que se consideram importantes para compor o quadro dos "fatos". As aspas visam destacar a concepção de que só há fato a partir do que é dito. Ou seja, a psicanálise demonstra que só haverá uma realidade de acordo com a abordagem discursiva que for utilizada para interpretá-la.

Em psicanálise é preciso lembrar que em todo saber constituído há uma dimensão de erro que consiste em esquecer a função criadora da verdade em sua forma nascente (Lacan, 1954-1955/1985, p. 30) e é para ela que a direção da supervisão se orienta. Somente ao se destacar do imaginário da experiência os determinantes simbólicos se apresentará o buraco do real. Ou seja, é a partir da apresentação de um quadro da situação clínica, no qual se situa o imaginário da cena tal qual pintada pelo supervisionando, que o supervisor poderá ressaltar as 
linhas simbólicas até chegar ao ponto sujeito, isto é, o ponto desde onde se vislumbra o “infinito de um olhar sem representação" (Quinet, 2002, p. 154).

Como exercício para sustentar tais proposiçóes, sigamos na linha de raciocínio do sonho da injeção de Irma. Freud, ao tentar situar-nos no contexto do sonho, nos deixa claro que ele estava tomado pela intenção de justificar-se com Breuer através da escrita da história de caso de Irma. Na primeira parte do sonho, é Freud quem tenta se desculpabilizar e, ao tentar entender o que se passa com Irma, tem um encontro que o deixa sem palavras. Nesse ponto, o sonho passa para uma outra cena em que se trata de uma espécie de discussão clínica de um caso em que Breuer (o Dr. M.) é chamado para dar seu parecer e na qual nem Freud nem Irma estão mais presentes. O resultado é que toda explicação acaba por revelar que um dos motivos da inquietação de Freud no sonho era resolvido ao ser apresentado o que se passou com um fato sem importância.

Mesmo que o tema deste artigo vise à supervisão e não propriamente às análises dos sonhos, constata-se uma relação tangencial nas duas abordagens. $\mathrm{O}$ que se verifica no sonho de Freud é que o impacto da clínica foi amortecido pelas explicaçóes, de modo que a implicação do sujeito diante da imagem, ou melhor, do quadro clínico, desapareceu para dar lugar à fala de outros a respeito do caso, sem implicação transferencial com a paciente. A analogia que se estabelece diz respeito a um certo tipo de procura por supervisão que busca uma explicação para o caso de forma a que a exposição não implique de maneira nenhuma o expositor. Porém, ao falar da situação clínica a um analista como "de um fato qualquer", a escuta demarca o lugar daquele que fala e permite uma outra visão. A super-visáo evidentemente não procura esquadrinhar - lembremos a ironia de Poe na busca da polícia pela carta roubada - os elementos apresentados sob modelagem do cientista, como se fosse um investigador que procura as e-vidências. Pois estas, por mais precisas que sejam, não permitem descobrir onde está a carta ou, no caso da supervisão, o elemento norteador do trabalho clínico. Para tanto, justamente, é preciso abster-se do campo da visão para que o olhar - ou melhor, a escuta indique o caminho a seguir. No caso do sonho de Freud, certamente não seria infrutífero, como indicamos, tentar identificar no caso apresentado o que fez com que o analista fosse tão afetado.

Portanto, na apresentação de caso em supervisão não é possível ter uma atitude supostamente objetiva como se os fatos não implicassem o analista na experiência. Mesmo em se tratando de um relato clínico supostamente objetivo, o eventual impacto (como no sonho), ou pelo menos o modo como é articulado, implica a fala do analista, que certamente pode procurar os motivos inconscientes que produziram tal efeito ou a forma como o quadro (clínico) é pintado por 
aquele que escuta. É certo que as impressóes que a fala do analisante causam no analista podem ser tratadas em sua própria análise, o que não o impede de que, ao tratá-las na supervisão, possa verificar os pontos nos quais a função operatória do desejo do analista deu lugar à manifestação de sua subjetividade.

\section{A janela}

No sonho da Injeção de Irma, Freud se refere a uma janela da qual procurou se aproximar para poder ver o que se passava com sua paciente, por julgar que em sua solução não havia considerado a possibilidade de algum mal orgânico. Uma janela - uma abertura ou ponto de luz - através da qual se poderia ver de modo mais claro o que se passava no quadro apresentado. Através dessa "janela” podemos vislumbrar Freud na figura de um médico que examina, através do olhar, a cavidade bucal da paciente com o intuito de identificar seu mal. Como é sabido, tanto pelo próprio Freud quanto através de Lacan (1954-1955/1985, p. 223), nessa cena pode-se apreender o que existe de mais angustiante na vida de Freud, seja no que tange às mulheres, seja em relaçáo à morte. Pois essa imagem enigmática que evoca o "umbigo do sonho" estabelece um para além daquilo que ali se mostra no qual o real pode ser tangenciado.

Pode-se dizer que, nesse quadro pintado pelo inconsciente, Freud representa a intenção de ser visto pelo Outro como aquele que sabe, que, com seu olhar penetrante, adentra no segredo de Irma. Nesse ponto ele ainda crê, como Guildenstern, ignorante na arte musical, poder fazer soar as notas da flauta que, metaforicamente, guardam o segredo de Hamlet (Shakespeare, 1602/2008). O efeito da imagem produz em Freud a surpresa pelo que vê, o que faz com que ele, como sujeito, desapareça, e seu eu se multiplique após esse encontro. O que foi visto ali que produziu tal consequência? Ele se depara com um real obturado pela imagem que ele gostaria que fosse vista pelo Outro. Porém ao narrar seu sonho ele se encontra nessa imagem que criou de si: um sujeito alienado ao saber da ciência, que, portanto, ignora, como um outro que julga poder furtá-lo do que não sabe (Lacan, 1966/1998: 251) e que vem interrogar tal saber. Pergunta-se por que Freud não acordou nesse ponto do sonho; argumenta-se que ele é "durão", pois, ao se deparar com a queda de tal alienação, não acorda para continuar sonhando. Segue no sonho até o ponto em que seu desejo de saber se transforma em saber sobre o desejo - cifrado na fórmula da trimetilamina, que se realiza no sonho, mas que só pode ser alcançada a partir da associação livre do sonhador, como um semidizer. 
No ponto em que aparece na tela a mancha, o estranhamento representado pelos cornetos brancos na garganta de Irma, a falha de Freud é enquadrada. Ele que via sua bela imagem passa a ser atropelado pelo que "isso mostra" (Lacan, 1964/1985, p. 76). Freud fica capturado na imagem que o deixa mudo - justamente na medida em que é pela fala no sujeito e não do sujeito que pode, ao passar pelo desfiladeiro do significante, ser propiciado o passo da subjetivaçáo. Para tanto, faz-se necessária a referência a um Outro. Ao se endereçar a palavra a outro, torna-se possível compor o quadro em seus elementos, destacando-se o ponto desde onde se vê o inaudível.

\section{A soluçáo}

Ao procurar encontrar a solução para o problema que se apresenta na cavidade bucal, Freud angustia-se diante da visão da carne. Mas justamente não era exatamente a referência à carne, ou melhor, ao corpo o que o levou a escrever a Breuer para explicar o caso? Não era a recusa da aceitação da soluçáo proposta por ele motivada pela consideraçáo de que o problema era de origem orgânica? Para além do motivo pelo qual o corpo seria causa de angústia, vale considerar que no momento seguinte Freud entrega os pontos e vai chamar alguém para ajudá-lo. Não seria normalmente essa a condição de quem procura um supervisor, sendo que este, com frequência, aprende muito com o trabalho sobre o caso e cujo acréscimo somente pode advir a partir da fala daquele que relata o caso? A solução que se apresenta na fala não advém justamente de uma boca que, ao mesmo tempo que cala ao referir-se ao corpo/sintoma, diz por onde pode advir a possibilidade de apontar ao desejo?

\section{Referências}

Freud, S. (1972). A interpretação dos sonhos. In S. Freud, Ediçāo standard brasileira das obras psicológicas completas de Sigmund Freud, v. IV. Rio de Janeiro: Imago. (Trabalho original publicado em 1900)

Freud, S. (1972). Perspectivas futuras da terapêutica psicanalítica. In S. Freud, Ediçẫo standard brasileira das obras psicológicas completas de Sigmund Freud, v. XI. Rio de Janeiro: Imago. (Trabalho original publicado em 1910)

Freud, S. (1972). Sobre o ensino da psicanálise na universidade. In S. Freud, Edição standard brasileira das obras psicológicas completas de Sigmund Freud, v. XVII. Rio de Janeiro: Imago. (Trabalho original publicado em 1918) 
Freud, S. (1972). Psicologia de grupo e análise do ego. In S. Freud, Edição standard brasileira das obras psicológicas completas de Sigmund Freud, v. XV. Rio de Janeiro: Imago. (Trabalho original publicado em 1921)

Freud, S. (1972). A dissecção da personalidade psíquica. In Edição standard brasileira das obras psicológicas completas de Sigmund Freud, v. XXII. Rio de Janeiro: Imago. (Trabalho original publicado em 1932)

Gay, P. (1988). Freud: uma vida para nosso tempo. São Paulo: Companhia da Letras.

Lacan, J. (1985). O seminário, livro 2: o eu na teoria de Freud e na técnica da psicanálise. Rio de Janeiro: Jorge Zahar. (Trabalho original de 1954-1955)

Lacan, J. (1985). O seminário, livro 11: os quatro conceitos fundamentais da psicanálise. Rio de Janeiro: Jorge Zahar (Trabalho original de 1964)

Lacan, J. (1998). Escritos. Rio de Janeiro: Jorge Zahar. (Trabalho original publicado em 1966) Lacan, J. (2012). O seminário, livro 19: ... ou pior. Rio de Janeiro: Jorge Zahar. (Trabalho original de 1971-1972)

Quinet, A. (2002). Um olhar a mais: ver e ser visto na psicanálise. Rio de Janeiro: Jorge Zahar. Shakespeare, W. (2008) Hamlet. In W. Shakespeare, Tragédias: teatro completo (pp. 545-602). Rio de Janeiro: Agir. (Trabalho original publicado em 1602)

Vegh, I. (2008) Análise de controle. In José A. Zuberman et al. (Eds.), Análise de controle (pp. 41-53). Porto Alegre: CMC. (Trabalho original publicado em 2001)

\section{Nota}

${ }^{1} \mathrm{O}$ termo ex-sistencia é utilizado por Lacan a partir de sua leitura de Aristóteles. No seminário 19 - ... ou pior, ele afirma: "Não há existência senão contra um fundo de inexistência e, inversamente, ex-sistere é extrair a própria sustentação somente de um exterior que não existe" (Lacan, 1971-1972/2012, p. 131).

Recebido em 07 de fevereiro de 2012 Aceito para publicação em 24 de novembro de 2012 